\title{
A la búsqueda del escultor de la Ilustración francesa. J. A. Houdon
}

\author{
Manuel Núñez Rodríguez \\ Universidad de Santiago de Compostela
}

RESUMEN:

Se analiza en este trabajo la obra del que transformó el retrato en el período de la Ilustración hasta el año 1792. Se trata del momento en que la Revolución es considerada como castigo divino tras la ejecución del Rey, con la renuncia de los nostálgicos del Antiguo Régimen a los filósofos de las luces, la masonería y los derechos del hombre, lo que supone cuestionar desde este momento el principio del individualismo. Es el planteamiento de partida de los personajes de Houdon para confirmar las pruebas sobre la personalidad. Sera con Napoleón cuando se llegue a un acuerdo con la Iglesia y Houdon reanude su labor como bustier dentro de los postulados del mundo neoclásico.

\section{PALABRAS CLAVE:}

Individualismo, Voltaire, contrarrevolución, estética neoclásica, Napoleón

\section{ABSTRACT}

It is the analysis of the work of the bustier that transformed the portraitin the Enlightenment period until 1792. The moment when the Revolution is regarded as divine punishment after the execution of King with the resignation of the nostalgics Old Regime to the philosophers of lights, Freemasonry, human rights, which is currently questioning from the principle of individualism. Approach starting characters Houdon to confirmwhether tests on personality. Will be with Napoleon when it reaches an agreement with the Catholic Church and Houdin resume its work as bustier within the tenets of neoclassical world.

\section{KEYWORDS:}

Individualism, Voltaire, counte-revolution, neoclassical aesthetics, Napoleon 
El arte del Siglo de las Luces (1741-1848) no se puede comprender sin profundizar en el estudio de la obra de Jean-Antoine Houdon (1741-1828). Ante todo, hay que poner de manifiesto que para aproximarnos a su realidad, se cuenta con las argumentadas consideraciones de Auguste Rodin, quien supo evaluar la importancia de las fuerzas motoras de su historial como bustier, conservado en el Museo del Louvre; planteamientos recogidos por su biógrafo y amigo Paul Gsell, quien también aporta sus propias iniciativas. Así hay una opinión con la que se ponen en marcha las búsquedas del presente trabajo. Es aquella en la que da cuenta de una observación que puede contribuir a aclarar nuestra idea de partida, sobre todo históricamente ${ }^{1}$.

En su criterio, la peculiaridad de J.A. Houdon, entre otras consideraciones cuyo juicio racionalmente fundado quedará para más adelante, era que: "los bustos que acababa de admirar, las reproducciones (sic)...con las que había escrito las Memorias del siglo XVIII (hacía referencia a los comentarios realizados por $\mathrm{A}$. Rodin sobre los bustos de Voltaire, Rousseau, Mirabeau, Franklin, entre otros emplazados en el M. Louvre), participaban de su crítica sobre los abusos de un régimen"2. Como se observará, a este propósito, no queda incorporada en su valoración el busto de Napoleón, Josefina, Mariscal Soult (correspondientes al 1806), como tampoco el del Mariscal Ney (1812); propuestas del siglo XIX donde se produce un cambio en las consideraciones de Houdon. Es decir, significativamente hasta el 1792, su propuesta quedaba centrada hasta la República y la honra de los grandes hombres. Por el contrario, en tiempo del Imperio hay un cambio sobre el concepto del líder por imposición del propio emperador. De manera que el reconocimiento nacional de los honores póstumos es distinto al de los Ilustrados. En consecuencia, el bustier surgido a partir de los años del Imperio dista de ser el escultor que antepone el registro de la verdad a la

Un estudio inapreciable sobre la categoría de la imagen como pensamiento figurativo y su metodología propia se corresponde con BOLVIG, Axel y LINALEY, Philippe (eds), History and Images; Towards a new Iconology, Turnnout, Brepols, 2003. Obra con la participación de autores como Francis Haskell.

2 RODIN, Auguste, L'Art entretiens réunies par Paul Gsel, Grasset, 1911, ch. VII, pp. 157-192.

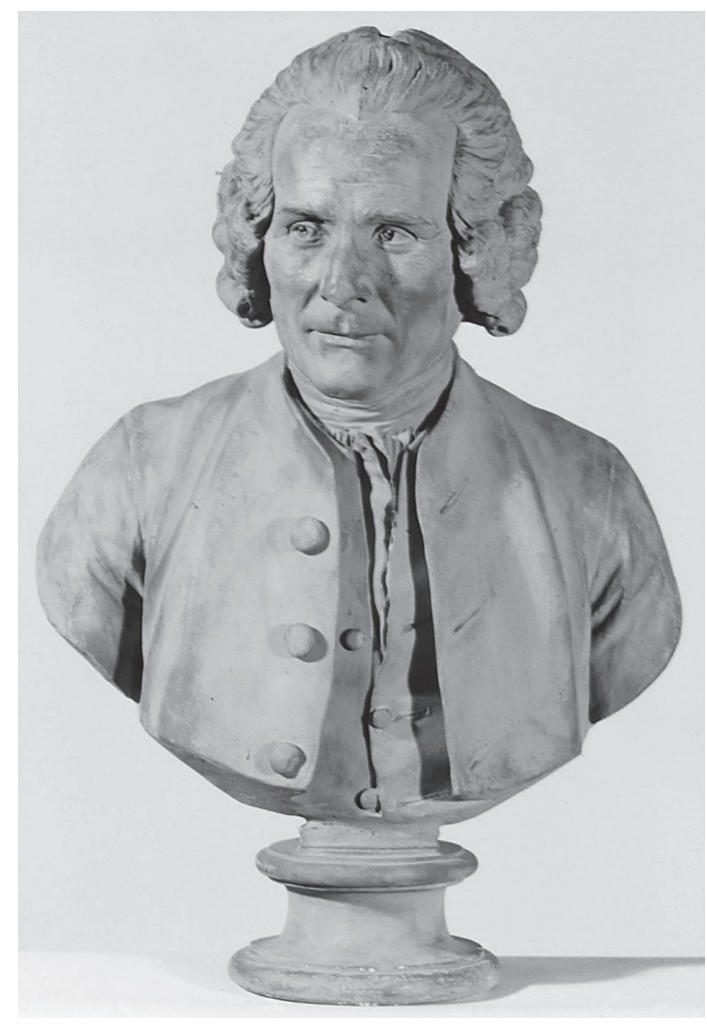

Fig. 5. J. A. Houdon: Rousseau (1778. Paris, Museo del Louvre)

conjetura o apariencia. Por si quedan dudas, el busto de Napoleón estaba experimentando un cambio hacia una cualidad esencial e inherente con la venusta. Concepto al que se añade el efecto inmaterialidad, acepción que suele usarse como atributo del alma.

Respecto a la afırmación de Paul Gsell, destaca con fuerza una preocupación retrospectiva. En su interés por reconocer la obra de Houdon, no descarta que constituyeran réplicas, posiblemente en bronce, necesarias para resucitar al personaje histórico, puesto que hay un hecho que resulta frecuente: las grandes épocas que habrán de sucederse en Francia después de Napoleón, habrán de retornar a nociones basadas en el clima mental de Voltaire y de Rosseau. Y, así, si cierto es que en el capítulo que Francis Haskell dedica a "El museo de los monumentos franceses" en referencia al expolio en el arte francés durante la República (septiembre 1792) con Alexandre Lenoir, se añade también la postura opuesta a partir de 1793-1796 por medio de una labor de rescate o pasión por las antigüedades, el mundo de las catedrales (en especial el Gótico) y a la vez la consideración de obras de los siglos XVI y XVII. Ahora bien, también es verdad que menciona como restau- 


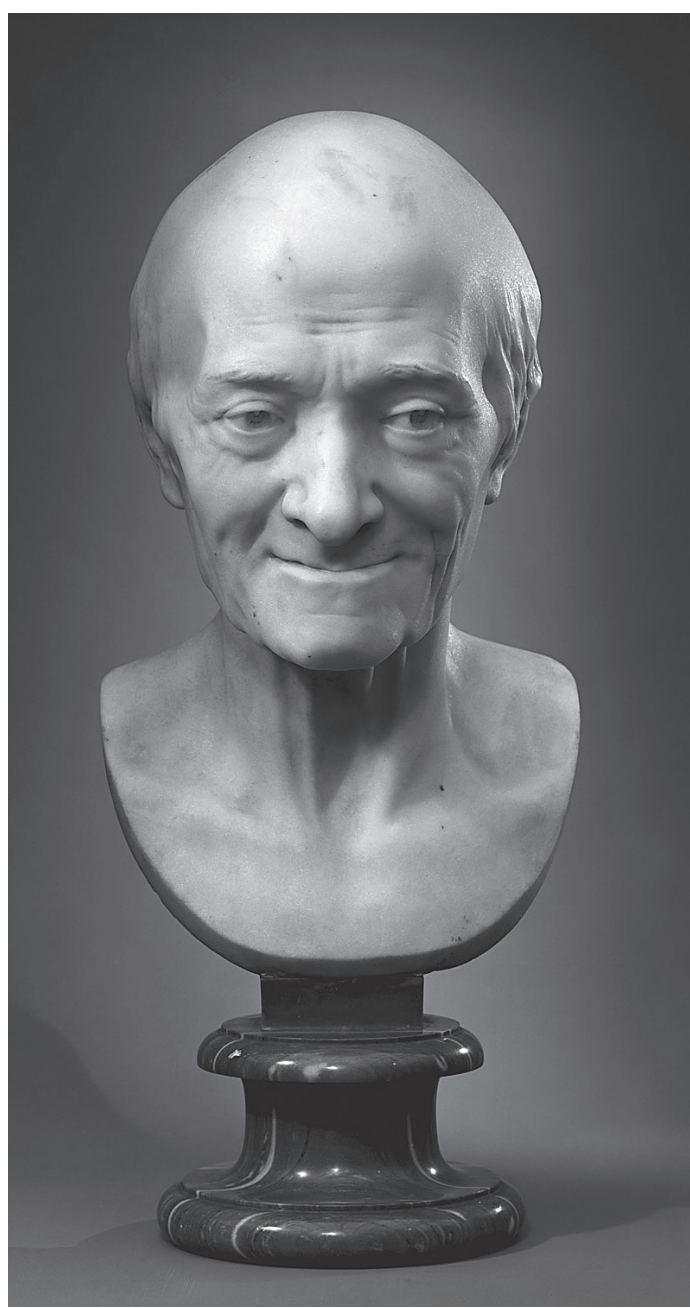

Fig. 3. J. A. Houdon: Voltaire (1778. Paris, Museo del Louvre)

radas efigies de reyes, nobles y cardenales, así como nuevos bustos para Descartes, Moliére, Pascal y sobre todo Winckelmann, a quien Lenoir admiraba ${ }^{3}$.

Sin duda quien habría de marcar el más decisivo de los cambios fue el consejero de comunicación de Napoleón, Vivant Denon (17471825), Ministro de las Artes del emperador y encargado de un concepto moderno de museo: la dirección del Louvre, heredero del llamado Museo de la Revolución. Este antiguo pensionado por Luis XVI en el seno de la Academia de Pintura y amigo de David, también lo era de Houdon y de Voltaire, a quien representaría en un retrato durante el verano de 1775 en Ferney. Hay que destacar, sobre todo, su densa labor en la restauración y acopio de obras destruidas,

HASKELL, Francis, La historia y sus imágenes, Alianza, Madrid, 1994, pp. 224-239. extraviadas y quebrantadas durante la Revolución, lo que supuso la reproducción de las conservadas en múltiples museos de provincias. Se trataba de dar un paso al que se deberá prestar atención, a pesar de la inevitable - y conscientemente oculta- represión, al ser un momento en el que, metafóricamente, se dispara con armas de fuego. ¿Razones? Se lleva a cabo una afluencia de obras que proceden de colecciones particulares, otros son desposeídos, al igual que iglesias, monasterios, el propio Versalles... Según parece, la cuestión era que la centralización se había convertido en un capítulo obligatorio. A este inventario habrian de sumarse los primitivos italianos y, por supuesto, las aportaciones desde Egipto. Cierto es que Vivant Denon ${ }^{4}$, por orden de Napoleón, no pudo dedicar su labor a la financiación de obras destinadas a la memoria de quienes configuraron las claves del mundo de la Ilustración, puesto que el emperador solamente estaba interesado por aquellos que fueran inhumados en los Inválidos y no en el Panteón (cementerio por antonomasia de Voltaire, Rousseau, Mirabeau...). Ello suponía un manifiesto interés por multiplicar el recuerdo de generales y oficiales, ahora sí, muertos bajo la Revolución, y en tiempos del Imperio ${ }^{5}$.

Bajo su supervisión, se realizan bustos y estatuas que marcaron un giro entre el 18 de Brumario de 1799, cuando Napoleón llega a primer cónsul y 1814. Si Antoine Jean Gros todavía representó al joven Napoleón de largos cabellos en la batalla del Puente de Arcole (1796, París, Louvre) con mirada enérgica y mentón dominante, por el contrario el busto de Houdon (1806) en terracota y mármol, participa de los principios del retrato de aparato. Pero la aportación más original es que Houdon suprime los criterios aplicados anteriormente sobre el carácter y los matices psicológicos. Igual ocurría con el Napoleón como Marte pacificador, colosal y heroico de Canova; un bronce clasicista concebido con varios ejemplos en los años posteriores al 1807-1809, rehusado por el propio

\footnotetext{
GUÉGAN, Stéphane, "Vivant Denon, conseiller en communication”, L'Histoire, n 244, juin 2000, pp. 23-24.

5 No hay que olvidar que en tiempos de la Revolución los enfrentamientos entre jacobinos y girondinos no están integrados por miembros de la milicia; y en cuanto a generales y oficiales, resulta obvio indicar que eran contrarrevolucionarios, lo que supone que sus doctrinas no dan cuenta de un punto de vista tolerante para los seguidores de los objetivos principales de los Iluminados.
}

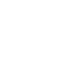




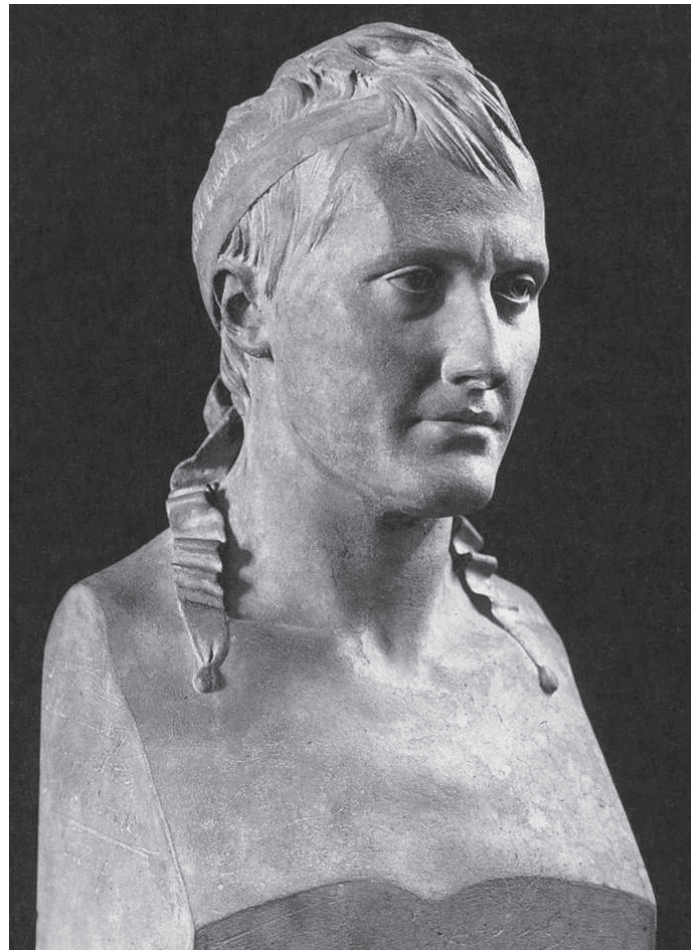

Fig. 7. J. A. Houdon: Napoleón I (1806. Paris, Museo del Louvre)

emperador en 1811 y que, como la escultura ecuestre del Emperador son imágenes para ver, no para interpretar. En cuanto se refiere a Houdon, parece que se debe prestar atención a los fundamentos activos de su estilo en esta nueva singladura, que no pasivos. Hay que subrayar como, en efecto, sus nuevas experiencias nada tenían en común con los mensajes icónicos de los ilustrados. Ahora la meta del retratista era la no revelación del carácter a través de los rasgos. Con todo, se puede emitir la afirmación según la cual, con una delimitación de medios muy notable, Houdon -sin desplazarse del locus como bustier en el que se encontraba- había logrado conseguir en 1806 la aprobación del Emperador con "la imagen más ideal del vencedor de Austerlitz" (Ph.Durey). De tal manera, conforme a este modelo donde los rasgos faciales de Napoleón son reconocibles, que había demostrado en su última obra la coordinación con la estética neoclásica. Ese mundo donde los personajes son identificados con los héroes del mundo antiguo y con la grandeur sobrehumana de las divinidades ${ }^{6}$.

DUREY, Philippe , "La tradition classique", en La Sculpture Française aun XIXe siècle, Grand Palais, Paris, abril-juillet 1986, pp. 288-301.
En el contexto de lo que fue la Primera y Segunda Guerra Mundial, se comenta la acción premeditada de muchos conocedores de las artes en su contribución al expolio. Aunque lo apuntado es transferible a muchas obras de arte, una categoría parecida hay que otorgar a muchos mensajes icónicos de los s. XVIII y XIX. Pero para utilizar evidencias, resulta necesario otorgar validez a un capítulo muy significativo sobre lo que pudieron haber sido posibilidades de rescatar en el futuro. A este propósito cabe recordar el manifiesto interés demostrado por uno de los padres de la Nueva Nación Americana, Jefferson, al marcharse de París e incorporar en su traslado bustos en yeso y terracota de Franklin, Voltaire, Turgot, La Fayette... para crear una "galería de notables" en Monticello. Resulta evidente que, de alguna manera contribuyó a rescatar parte de la obra de Houdon expoliada. Si es verdad que muchas imágenes parecen investidas de poder - como los Burgueses de Calais con distribución mundial-, con esa cualidad parecen estar dotadas aquellas de Voltaire que recobran vida en manos de Houdon en múltiples museos americanos. Esto impone como respuesta posible la reelaboración a partir de un original y en razón de la popularidad del modelo y sus ideas. Cualidad ejemplificada asimismo en las múltiples propuestas sobre Rousseau.

En la actualidad muchas de aquellas obras, conservadas en Virginia y el Metropolitan $\mathrm{Mu}-$ seum of Art de N.Y., entre otros, fueron estudiadas y analizadas en universidades americanas por historiadores del arte, comenzando por la universidad de Eaton, Taft, como analiza Anne Pingeot, conservadora del Museo d'Orsay, quien incluso recuerda una cuestión muy interesante: así como apareció un estudio sobre la escultura francesa del siglo XVI al XIX en l'Ermitage en el año 1963 sin embargo, añade, en lo que se refiere a Francia los libros sobre escultura a duras penas destacan en las bibliotecas; es decir, su país da cuenta de una situación bastante precaria a lo que en el pasado fue "la gloria de nuestros escultores, cuando -añade- se consagran fastuosos volúmenes a pintores muy secundarios"7. No sorprende entonces que previo a los dos volúmenes dedicados por Louis Reau a Houdon en 1964, el trabajo más antiguo se corresponda con la valoración hecha por Giacometti en 1928.

PINGEOT, Anne, “Introductión”, en La Sculpture, p. XIX. 
El escultor y las particularidades de su lenguaje visual

Houdon, nacido en Versalles el 20 de marzo de 1741 , se nos ofrece como un referente para un conocimiento, a través de los retratos, de la sociedad de su época, de quienes fueron los maestros capitales en la práctica insobornable de la razón ilustrada, de igual modo que en la promoción de la libertad individual, el rechazo dogmático, los derechos humanos...; planteamientos analizados en los escritos de su promotor Diderot y d'Alembert, autores de la Enciclopedia, así como partícipes de los salones femeninos. En efecto, ante cámaras donde se confirmaba, en consideración de U. Eco, "el papel de las mujeres y la aparición de los temas artísticos".

En este sentido, parece útil considerar que los receptores de la comunicación en el Círculo de Auteuil, guiado por Mme. Helvetius, fueron entre otros d'Alembert, Diderot, Mirabeau, Condorcet, Voltaire, Houdon, La Fayette, así como Franklin y Jefferson ${ }^{9}$. Entre los presentes resultaba de gran importancia la crítica de arte del polifacético Diderot, un verdadero escritor de ágil pluma que, además, reiteraba sus consejos en los Salones donde, entre otras aplicaciones, señalaba "hemos de hacer odioso el vicio, notable el ridículo y valorar el decoro", sin olvidar que bajo el cincel del escultor pueden surgir asimismo símbolos históricos, testimonios ${ }^{10}$. Se nos pone en guardia en el afianzamiento de un principio que contribuye a entender mejor las diferencias de interpretación que provocaron su enfrentamiento entre el que fuera teniente general Conde de Caylus, fundador de uno de los dos concursos anuales de l'Ecole de Beaux-Arts (14 de agosto de 1760), y Diderot, por cuestiones de método.

Aunque la interpretación exhaustiva pueda ser compleja, la cuestión es relevante por su significado y requiere una valoración detallada, por factores de decisiva influencia; lo que

ECO, Umberto, Historia de la belleza, Lumen, Barcelona, 2007, pp. 252-254.

9 Se dice que Jefferson es quien persuade a Houdon para realizar el viaje a América en 1785, donde da forma a los símbolos de la Guerra de la Independencia, al padre fundacional (las representaciones de G. Washington), al autor de la declaración de la Independencia americana (Th. Jefferson), B. Franklin...

10 RICHARD, Andrè, La crítica de arte, Cuadernos 54, Eudeba, Buenos Aires, 1972, cfr. cap. 3 "Criterios canónicos" y cap. 4 "Criterios históricos". nos obligará a detenernos y analizar más detenidamente el contenido de lo formulado. Y es que el análisis requiere distinguir y evaluar la plenitud del sentido del texto de Descartes sobre las Passions d'Âme (París, 1649), que han sido básicas en la estructura del lenguaje de la imagen, o como propone A. Rodin, la expresividad del rostro. Planteamientos de gran interés en los trabajos de la Academia de escultura de Caylus, instigadora del retorno a la Antigüedad $^{11}$. Aspectos que pasaremos a considerar en páginas sucesivas.

Ninguno de los estudios realizados hasta el momento sobre Houdon agota su análisis valorativo. De una manera muy especial habrá que tener en cuenta las revisiones observadas por Rodin durante su visita al Louvre, donde los bustos de Voltaire y Rousseau sorprenden a este gran escultor, definiéndoles como "el Diógenes, personificación de la malicia (Voltaire), frente al misántropo que se lamenta a veces con razón de ser perseguido (Rousseau)" ${ }^{12}$. Esta afirmación, que ahora supone sólo un anticipo, se complementa con la impresión profunda de los rostros y "la mirada descifrando las almas de Franklin, el gesto provocativo del orador y presidente de la Asamblea, Mirabeau, la actitud jubilosa y bella de Mme. Houdon, como prototipo de la elegancia natural y carente de la mirada atormentada" (Condorcet); como también sorprendía a Rodin la diablura y picardía que Houdon sabía aplicar a los niños como expresión de sus aspectos emocionales.

Por lo demás, junto con la fuerza de la belleza en la mujer, añadía algo que resulta muy importante: "no se puede juzgar por la apariencia, puesto que el aspecto mismo del gato nos advierte al que lo estudia atentamente cuánto hay de crueldad escondida bajo su somnolencia hipócrita. Pero un fisionomista sabe distinguir entre el zalamero y el bondadoso. ¿Cuál es entonces el cometido del artista? Que la verdad cobre fuerza incluso bajo el disimulo"13. Junto a esta impresión añadía un dato sobre la actividad escultórica del retratista, y que se debe tener en cuenta para los vínculos de Houdon con Voltaire, cuya obra llegaría a interesar a la propia Catalina de Rusia; tal fue un segundo ejemplar en mármol de Voltaire sedente, la obra

\footnotetext{
11 LE NORMAND-ROMAIN, Antoinette, "II, 3. Concours de la tête d'Expression”, en La Sculpture.., pp. 42-48.

12 RODIN, Auguste, op. cit., p. 63.

13 Ibidem
} 
cumbre de Houdon (1781), encargada por la sobrina del intelectual. Dotada de un discurso emocional único, Houdon supo captar en esta statufié vivant, verdadero privilegio regio, con la mirada oblicua de quien olfatea la bellaquería, el carácter capital del grito de guerra de este filósofo: combate el fanatismo, la injusticia y la intolerancia, para defender la razón, la humanidad y la indulgencia. Es decir, todo cuanto contribuya a resolver la tragedia del ser humano.

En esta imagen vivo-parlante del Voltaire sedente en la Comédie française, se hace patente una cuestión de fondo de máxima importancia. En su quehacer hay un factor de decisiva influencia que requiere conocimiento y práctica para que esta escultura en la plenitud de su discurso icónico (se trata de que emerja con evidencia la personificación de la inteligencia) pueda mantenerse libre en el ámbito espacial de referencia. La tensión psíquica así lograda con el interlocutor, al ser decisiva la empatía, tiene como referente insustituible la mirada. Por ello, antes de comprobar la transformación incesante en su pluralidad como bustier, al igual que la atención concentrada en la percepción visual y la exploración psicológica, ¿cuáles fueron los criterios de su productividad?; ¿dónde entró en contacto con el mundo clásico, los conocimientos anatómicos, la escuela ceroplástica con modelos de tamaño natural, los estudios referidos al ojos humano y al globo ocular...?; ¿no fue en Italia donde practicó el salto desde la subjetividad del gusto espiritual, a la subjetividad del gusto corporal, con el empleo del escalpelo, ajustándose en la elaboración de su l'Écorché (1767) a modelos realizados en el Museo Specola de Florencia?

$\mathrm{Y}$ es precisamente este modelo anatómico sobre la musculatura humana (Roma, Villa Medicis) el que le induce a un cambio de dirección, precedido por el estudio científico, con las posibilidades constructivas de la razón como medio. Así, comprende que debe de ser manifiesta la forma de conocer la causa, el origen, siempre con pruebas; manera de no derivar hacia la inseguridad, puesto que la fase científica del conocimiento se basa en la observación y la experiencia. Sólo así se llega a lograr la explicación de la mecánica del cuerpo; de los músculos de la expresión facial, que afectan intensamente a la manifestación de las pasiones. Ahora bien, ¿se podría considerar que sus planteamientos proceden de una interacción inicial con la ex- periencias llevadas a efecto en sus grabados por Charles Le Brun?; trabajos inspirados, a su vez, en Las Pasiones del Alma de Descartes, quien "situaba la sede del alma, no en el corazón, sí en el centro del cerebro, de manera que el rostro era la parte del cuerpo donde el alma deja ver lo que siente, en tal sentido los ojos, y en especial las cejas, contribuyen al realce de la mirada como fuente de información" ${ }^{14}$.

\section{Análisis crítico de su obra}

$\mathrm{Al}$ consultar el cuadro cronológico de su labor, se observa que su fiebre creativa se detiene en torno a 1792, para volver a ser retomada con la llegada de Napoleón; sin embargo, el efectivo desarrollo de su habilidad coincide con los años previos al Terror (1792-1794), lo que supone experiencias más breves con el Primer Imperio (1804-1814).

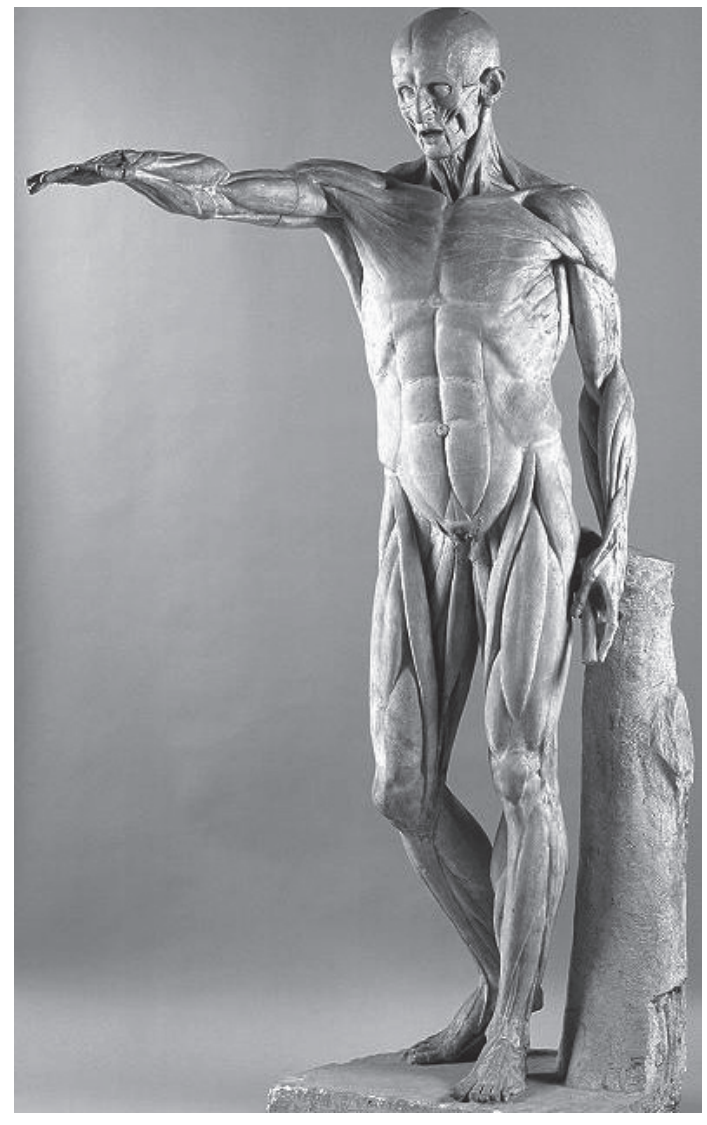

Fig. 1. J.A. Houdon: L'Écorché, un modelado anatómico del cuerpo solo con la musculatura (1767. Roma, Villa Medicis).

14 LE NORMAND-ROMAIN, Antoinette, op. cit., p. 43. 
En líneas generales, fue un escultor que dispuso de una clientela amplia e internacional. Con conocimiento y experiencia acumulada en Italia, a donde se traslada para poner en práctica su Premio de Roma en escultura en 1761, la información y la experiencia le permiten llevar a cabo actividades demostrativas de su esfuerzo en el aprendizaje. No obstante, para llegar a una imagen clara y unitaria de quien destacó en la actividad retratística, hay que hacer referencia a la representación plástica, a la estatuaria. Así, independientemente de su obra posterior en Francia sobre Jesucristo entregando las llaves a San Pedro (1776, para Santa Geneviève de París, destruida durante la Revolución), se impone una información sintética sobre San Bruno (1766, Santa María de los Ángeles, Roma). Se trata de una propuesta que puede servir como antídoto a la de su maestro Slodtz (1705-1764), quien también trabajaría en Roma desde 1728 a 1745. En la obra de este (1744, mármol, nave San Pedro de Roma), queda planteado un estudio del gesto donde los sentimientos quedan regulados por las leyes que gobiernan las cargas emocionales del barroco. Estímulos emotivos carentes en la obra de Houdon, para fomentar el sentimiento y el silencio que desencadena el acto reflexivo; el efecto "gravedad estoica", consustancial con el mensaje de la orden cartuja. Pero, aun tratándose en buena medida de una escultura que se resuelve con carácter experimental, no llega a ser una obra de tesis como su célebre Morfeo. Pieza elaborada en mármol (1777, M. Louvre) con la que fue admitido en la Academia Real de Pintura y Escultura, y sobre la que un periódico francés añadía: "Houdon además hace hablar a sus obras".

En Italia entró en contacto con los vestigios arqueológicos de las ciudades vesubianas recién descubiertas de Herculano (1739), Pompeya (1749), de igual manera que los templos griegos de Paestum en un momento de verdadera fiebre por la Antigüedad. Todo ello en vísperas de la Revolución ${ }^{15}$, hecho que transformaría el gusto de Occidente. Pero este interés por el clasicismo de Esparta, Atenas y la Roma Republicana ${ }^{16}$ tampoco fue decisivo para abandonar el

15 Confrontar para este apartado GRELL, Chantal, Le dix-huitiéme siècle et l'antiquité en France, 16801780. 2 vols, Voltaire Fundation, Oxford, 1996; Ecco, U., Historia de la Belleza..., pp. 244-251.

16 CORNETTE, Joël, "Comment le Siècle des Lumières a découvert Pompei” en L'Historie 209 (1997), pp. 16-17. concepto clasicista de la imagen renacentista, de igual manera que para examinar y reflexionar ante obras tan importantes como el David de Miguel Ángel en Florencia. Un ejemplo tan importante para Houdon, puesto que la mente no es independiente del resto del cuerpo; especialmente la manera de plantear el rostro con ceño fruncido y mirada amenazante, con las pupilas orientadas. Sabido es que la decisión de Miguel Ángel tampoco era una cuestión azarosa, puesto que, al igual que Leonardo, se dedicó a los estudios del tejido óseo, de igual manera, que a la osteomiología ${ }^{17}$, aportando unas tablas donde quedó demostrado su conocimiento de los músculos, sin pasar desapercibido el aparato locomotor.

Llegados a este punto parece patente una razón de fondo. Es posible que Houdon a la vez que educa su visión, sus facultades de observación, su trabajo manual en materiales distintos durante su estancia en Italia, se sensibilice con el cuerpo desnudo del hombre y los problemas de anatomía, escorzo, ritmos en reposo o movimiento y musculatura. Y así, una vez logrado en 1761 el Premio de Roma, su formación quedara centrada en el estudio del mundo del Renacimiento, pero también de la Antigüedad.

L'Écorché (1767 Roma, villa Medici). Sobre esta obra existen muchas incógnitas. En principio, L'Écorché queda también aplicado a alguna figura de tamaño natural del Museo La Specola (Florencia), que tuvo como primer director al anatómico italiano Felice Fontana (1730-1805), estudioso de la anatomía del ojo humano, según quedó indicado en párrafos anteriores. Antes de proseguir, y puesto que se imponen las dudas, hay que platear el interrogante: ¿el denominado Decorticato o Despellejado (M. Bargello) de Ludovico Cigoli (1538-1613) no pudo haber sido un preámbulo a las estatuas y moldeados sin la piel de La Specola?; durante los años que permaneció en Italia, ¿fue conocedor del cuerpo humano con los músculos en superficie tal como se registra en la impresionante figura de San Bartolomeo de Bronzino (1555 Roma, Accademia di san Luca)?. Resulta más problemático saber si llegó a otorgar relevancia a los cadáveres como modelos; se cita, entre diversos artistas ceroplásticos a Clemente Susini (1754-1814), creador de una importante escuela

BUSSAGLI, Marco, Il corpo humano. Anatomia e significati simbolici, Mondadori, Milano, 2005, pp. 266-343, 362 y 363. 
donde deja sello de una pericia excepcional los denominados "músculos miméticos del rostro"; es decir, aquellos que se asocian a los estado de ánimo y emociones de la expresión facial; tales son los que se conservan en el Museo de La Specola, sala 20.

Las circunstancias del momento no permiten detenerse para analizar más detalladamente las propuestas que guían el conocimiento sobre la condición humana. Y en ello deberá hacerse patente el conocimiento y la experiencia acumulada. En tal sentido, se estaba produciendo una revolución científica que ayudaba a cambiar la situación, al tiempo que se abogaba por asegurar la difusión de atlas sobre anatomía, cirugía, disecciones hospitalarias... Por ejemplo, Clemente Susini envió desde Florencia a Austria y Francia modelos de la escuela ceroplástica de tamaño natural para enseñar la anatomía humana, patológica y comparada; Felice Fontana remitió las obras de Govard Bidloo (1649-1713), de Bernard Albinus (1697-1770), Tabulae sceleti et musculorum. En definitiva, estos textos con notas y láminas sobre los músculos y vasos sanguíneos visibles, la anatomía y la cirugía, hacían patente el nuevo concepto de la ciencia debido a la Ilustración, quien proponía salir del mundo de la utopía y de la pasividad en las valoraciones.

Decía Kant que la Ilustración significaba la salida del hombre de su culpable minoría de edad. Minoría, en tanto que discapacidad para servirse de su propio entendimiento, sin la orientación o consejo de otro con mayor criterio y rechazo al planteamiento dogmático. No hay duda que Houdon rehúye desde muy temprano los preceptos académicos para censurar las normas y dar paso a lo que determina la sensación de una manera de ser. Si cierto es que la belleza neoclásica marcaba el estilo de aquella segunda mitad del siglo XVIII, al margen de los planteamientos canónicos y en un momento definido por la razón, cuando la revolución cultural sostenida por la Ilustración siente la necesidad de experimentar y de conocer para avanzar, y puesto que la libertad también contribuye a poder superar el aquilatamiento de la ignorancia, el intelectual-artista dispone de una cierta independencia. De manera que sus criterios de valoración responden cada vez más a un conjunto de factores que son el resultado del reclamo del mundo clásico, pero junto con la mímica inspirada en el teatro, estaba dando paso a un capítulo nuevo cada vez más próximo al naturalismo, puesto que si por algo se caracteriza su obra -como decía el propio Ro- din- es por ampliar el encuentro de tres factores: efecto tensión, efecto vida (cuerpos en acción vital) y evitar los efectos congelados, para insinuar el efecto superficie viva. De esta manera se experimenta un claro interés por las fuerzas en acción, por proponer las cargas emocionales y los estados anímicos tan consustanciales con sus retratos. Por lo demás, para bien o para mal, aun cuando en Roma conoce la obra de Bernini y el mundo de la Antigüedad, sus señas de identidad le llevan a combinar el idealismo griego y el realismo romano.

El Decorticato (l'Écorché) representa al humano desollado luego de haberle extirpado la piel, adiposidades y tejidos. El resultado muestra una identidad óseo-muscular con venas y articulaciones al aire. Aquí no se puede emprender la tarea de argumentar posiciones, pero la consideración que a veces se ha emitido como "imprecisión anatómica" resulta exagerada y probablemente surja de no haber sido aprobada en París en el Salón de estatuas de mármol a gran escala. Sin embargo, fue admirada por Diderot y d'Alembert, quienes asumieron que había demostrado su comprensión de la anatomía humana. Sobre esta obra existen dos modelos. Uno se representa con la diestra en horizontal a la manera de los despellejados, con músculos y vasos sanguíneos visibles del Museo de Historia Natural de la Specola de Florencia; este ejemplo tiene varias reproducciones y variantes. Cuando regresa a Francia y en 1777 Houdon pasa a ser miembro de la Academia Real de Pintura y Escultura y de la Escuela Superior de Bellas Artes de París, al tiempo que se encarga de la enseñanza, en la segunda hace entrega de otro l'Écorché en el que experimenta un cambio al mostrar la diestra articulada en ángulo; y, sobre todo, resaltaría que el autor, además de abordar el efecto transición o paso de una postura que insinúa la segunda, comprende el aparato locomotor para insinuar que no hay vida; o que el concepto de vida resta asociado al movimiento, al ritmo.

En Rodin, gran admirador de Houdon, el planteamiento será a la inversa: la palpitación de vida, de energía, se insinúa bajo la piel, bajo las superficies onduladas (henchidas o hundidas), creando una elasticidad o efecto vibración al que contribuye la luz y la penumbra ${ }^{18}$. Para proporcionar un interesante medio para contrastar, habría que reparar asimismo en las obser-

\footnotetext{
18 ALBRECHT, Hans Joachim, Escultura en el siglo $X X$, Blume, Barcelona, 1981, pp. 86 y 159-160.
} 
vaciones transmitidas por Rodin a Paul Gsell ${ }^{19}$ y tener en cuenta que entre los modelos anatómicos utilizados por los alumnos en Bellas Artes figuraba este Desollado de Houdon y la Edad de bronce de Rodin.

\section{El bustier de la Ilustración}

A su regreso de Italia Jean-Antoine Houdon se impone como artista de los nuevos tiempos y como ciudadano, cuando su extensa labor como retratista de mentes líderes de los personajes más importantes de la sociedad del momento, da paso a un creador independiente, equiparable con las labores reservadas a los denominados hombres de genio en el templo de las Glorias Británicas. Su labor no estuvo destinada a transmitir mensajes o conmemorar hechos históricos, sí en cambio a subrayar los rasgos expresivos que busca en todo retrato como manifestación de una personalidad, de lo distintivo, de lo característico que define a una conciencia, lejos de reflejar la fidelidad a una apariencia. En otras palabras, rehúye el prototipo, pero también procura establecer un equilibrio entre la noción de identidad ante la gran importancia de la verosimilitud, de manera que sus rostros son la demostración del enunciado lógico del ente; es decir, son las notae individuantes útiles para la revelación de una conciencia $^{20}$.

Antes de acceder a los criterios que estructuran el mensaje o significado de las obras de este bustier, que tan bien supo evaluar la expresión icónica de la persona pensante, hay una cuestión a considerar por su importancia y que, todavía hoy, resulta de especial valor.

En el panorama bibliográfico, poseen carácter obligado las referencias a Georges Giacometti y, especialmente, a Louis Réau ${ }^{21}$. Sin embargo, desde el punto de vista científico y con una crítica racionalista, resulta obligado recurrir a las afirmaciones de A. Rodin, cuando analiza con orgullo sus retratos. En efecto, partiendo de un principio global, sus manifestaciones

19 GSELL, Paul, op. cit., pp. 157-192.

20 FREEDBERG, David, El poder de las imágenes, Alianza Editorial, Madrid, 1992, cfr. pp. 440-441.

21 GIACOMETTI, Georges, La vie et l'oeuvre de Houdon, 2v. (Paris 1928); RÉAU, Louis, "Houdon sous la Révolution et l'Empire", Gazzette des Beaux Arts, jullet-aout 1924, II, pp. 59-68; Id., Houdon. Sa vie et sa oeuvre, 2 vols. Paris, 1964. preparan al lector para un criterio más amplio, donde no deja de ser significativo el valor que se le confiere a la calidad de la obra... Pero la envergadura del proyecto emprendido por el bustier nunca dejará de ser un indicador fiable propius, individual. Y así, al considerar ambos criterios, añade:

“a veces el oficio del artista exige más habilidad manual que inteligencia. Basta con observar un buen busto para salir de este equívoco. Así, los bustos de Houdon están escritos como capítulos de Memoria. Es decir, época, familia (procedencia), profesión, carácter personal, todo queda indicado”. La comparación le impresiona tanto que no duda en aceptar el carácter esencial de su obra, en juicio de su amigo Paul Gsell: "Si Houdon ha escrito las memorias del siglo XVIII, vos habéis redactado las del siglo XIX. Vuestro estilo es más rudo, menos elegante, más dramático. El esteticismo del siglo XVIII cobra valor en Houdon, sus personajes más sociables. Ellos son portadores de la crítica sobre los abusos del régimen"22.

No se puede ignorar que los autores de la sociedad ilustrada asociados a la Revolución denunciaron un orden para dar paso al otro dictado por la razón y la libertad -como tantas veces quedó indicado- para proclamar un estado federado el 14 de julio de 1790, para reelegir su destino. Situación que ya no se correspondería con la III República, con la época de Rodin, puesto que las circunstancias eran otras. En consecuencia, Paul Gsell haría la siguiente observación sobre sus bustos: "los vuestros, por el contrario, parecen poner en cuestión el valor mismo de la vida humana y experimentar la angustia de deseos irrealizables”. La respuesta de Rodin sería inmediata: "mis bustos han desagradado a menudo, puesto que fueron siempre muy sinceros, pero tienen un mérito, la verdad"23. El sentido sobre el principio verdad obliga a revisar los criterios: si para Houdon está en relación con la representación de una personalidad, de lo característico y lo que le define, conforme a los rasgos expresivos útiles para la revelación de una conciencia, en la propuesta de Rodin los reproches recibidos, muchas veces por los aspectos innovadores eran,

\footnotetext{
2 GSELL, Paul, op. cit., pp. 170 y 191-192.

23 Ibidem, p. 191-192.
}

77

\section{.}


como él mismo decía, por buscar inspiraciones más literarias que plásticas, incluso añadía "lo que importa es que el público encuentre placer, puesto que la pintura, la escultura, la literatura y la música están más próximas entre sí de lo que la gente se cree" ${ }^{24}$.

Lo sorprendente es que todavía estamos en condiciones de reconocer la valiosa importancia de A. Rodin y comprobar, por el contrario, la ausencia que existe sobre A. Houdon llegado el momento de avanzar en conocimientos, como también de revisar criterios, en textos sobre la escultura del XVIII-XIX. En el panorama de lo existente, se impone la cita de Anne L. Poulet, quien se refiere a Houdon como "el mejor escultor del mundo", proponiéndole en su enfoque como el completo escultor del retrato europeo de finales del siglo XVIII ${ }^{25}$. De igual modo, el ya citado Guilhem Shcherf señala que renovó el arte del retrato en Francia. Asimismo, cabría recordar la observación de Howard Hibbard ${ }^{26}$ al confirmar que de los cuatro escultores formados junto al magnifico retratista Jean-Baptiste Lemoyne (1704-1778), Pigalle, Falconet, Pajou y Houdon, solo reconoce en el último una mejor preparación para aparejarle. Y sin embargo, su reputación ocupa en muchas ocasiones un puesto polémicamente sorprendente. Sin considerar otro ejemplo, está la actitud beligerante de Rudolf Wittkower con Houdon, frente al énfasis con Pigalle ${ }^{27}$.

En lo más concreto de su trabajo como retratista, las dimensiones aplicadas se corresponden con los principios de la Ilustración, cuando el redescubrimiento de cuanto constituye la infinita variedad de sentimientos y pasiones pasa a influir en los aspectos emocionales. Los significados connotados por la fe en los valores de la razón muestran como el hombre comienza a acceder como individualidad y a dejar de reconocerse hombre en el mundo. Y a medida que se alarga el campo de reclutamiento de las nuevas identidades, en este marco de singularidades van cobrando entidad filóso-

4 Ibidem.

25 POULET, Anne, J. Antoine Houdon, El escultor de la Ilustración, University of Chicago Press, 2003; HALLAM, John S., "Houdon's Richmond E. Washington", American Art Journal, 10, nov.1978, pp. 73-80.

26 HIBBARD, Howard, Les chefs-d'oeubre de la Sculpture Occidentale (de Moyen-Âge a nous jours), Edita S.A., Lausanne (Suisse), 1977, p. 227.

27 WITTKOWER, Rudolf, La escultura: procesos y principios, Alianza, Madrid, 1980, p. 238. fos, escritores, periodistas, benefactores de la humanidad e, incluso, el buen revolucionario que había consolidado su condición y era digno del palmarés político en el Panteón de París (siempre excluyente con el soldado desconoci$d o$, conmemorado en el Carrusel e inhumado en los Inválidos).

Por consiguiente, en la labor del bustier Houdon resulta razonable aplicarse por el rédito de la verdad. Y en esta cadena hacia la precisión, hacia la verosimilitud, también es preceptiva la razón; no para transcribir, sino para manifestar los aspectos esenciales del carácter capital de quien queda determinado por su manera de ser. De esta manera, en la medida que son censurados los preceptos académicos, al considerar unos rasgos faciales, un rostro, en su calidad de ser los rasgos expresivos de una fisonomía, representan las pruebas útiles para la revelación de una personalidad; de un yo, de un sujeto o alma. Bien es verdad que en algunos casos las personalidades representadas, por su condición de mentes creativas o líderes anteriores a El Terror (1792-1794), posterior a los años de la Revolución, son símbolos de una importancia fundamental y, no pocas veces, en los límites del verdadero documento. Lo que explica que en el Panteón se justifique la memoria de dirigentes o mandatarios anteriores al período 1792-94, momento del desgarramiento o denuncia de la filosofía de las Luces.

Se ha considerado siempre que la representación del busto de Denis Diderot (1713-1784), realizado a la vuelta de Italia en 1771 (Museo del Louvre), es la propuesta más importante que en un primer momento demuestra hasta qué punto logra superar la noción de una identidad, puesto que sus rasgos son expresivos de una identidad, aunque bien es cierto que mostrándole como un pensador de la antigua Roma. Pero no por ello el fundador de la $E n$ cyclopédie ve alterada su condición, puesto que se consideraba a sí mismo un actor en el teatro del mundo, si bien caracterizado por una gran exigencia.

Este amigo y consejero de Catalina II de Rusia, al igual que Voltaire, será quien contribuya a que Houdon realice un busto de la emperatriz (1773), hoy en el Museo del Hermitage. El principio que rige este retrato de aparato, como el de María Antonieta, nada tiene que ver con los conceptos al uso que sobre la cabeza (la parte más importante de la anatomía humana) y la faz (lo que contribuye por sus formas a reve- 
lar los componentes de la identidad individual) que constituyen los elementos que el artista consigna con exactitud. Ahora bien, la facies inspira varias interpretaciones, al asociarse al concepto apariencia. Y es que en cuanto a sus orígenes, al proceder del verbo latino facere -hacer, y por extensión representar-, en criterio de Marco Bussagli la expresión facial es sinonímica, asimismo, de simular, aparentar, representar ${ }^{28}$.

Ahora bien, Rodin supo descifrar el método que determina los gestos del rostro en las imágenes-busto de Houdon para expresar una cuestión que no responde precisamente a la tesis de la apariencia o probabilidad: si el artista no reproduce más que los rasgos superficiales como podría hacerlo la fotografía, o si consigna con exactitud los rasgos de un semblante pero sin dar cuenta de un carácter, abstengámonos; tal era su criterio, pero además añadía, "no es merecedor de nuestro reconocimiento" 29 . Y es entonces cuando Rodin plantea una cuestión relacionada con el entendimiento, considerado como una facultad del alma a la que se le atribuyen tres connotaciones: memoria, enten-

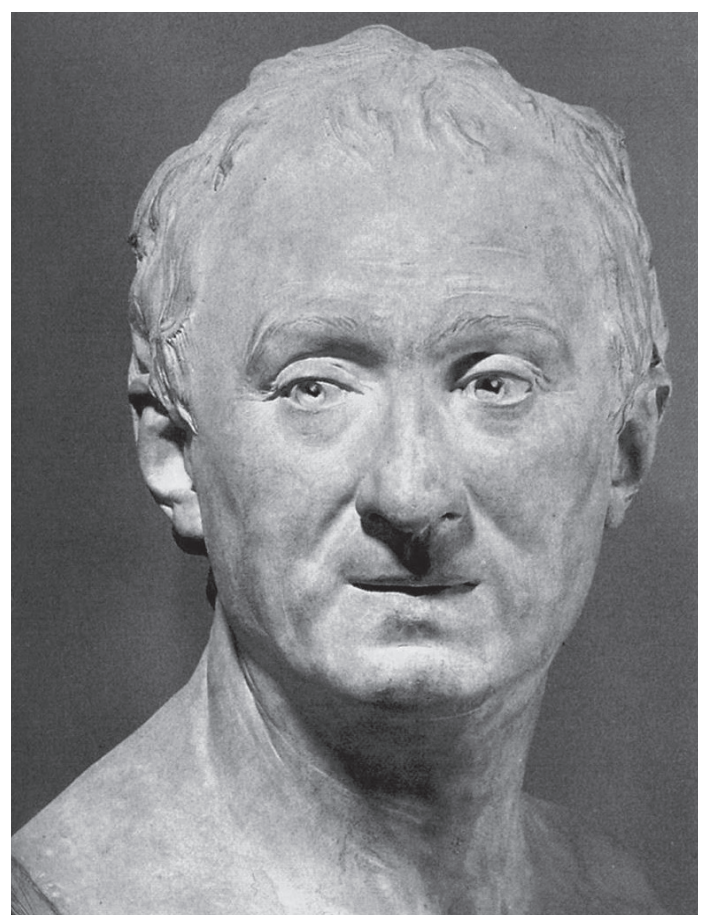

Fig. 2. J. A. Houdon: Denis Diderot (1771. Paris, Museo del Louvre).

28 BUSSAGLI, Marco, op. cit., p. 262.

29 GSELL, Paul, op. cit., p. 162. dimiento y voluntad ${ }^{30}$. En su declaración sobre Houdon, la idea central apunta a un objetivo prioritario: el rostro no deberá estar en disconformidad con el alma. Por otra parte, la mirada, al llevar marcada la transparencia de las niñas oculares perforándolas, fileteándolas, comunica mejor las circunstancias de un rostro adornado con sus verdades; por el contrario, una impresión afectiva venía a confirmar como en el arte de comunicar hay que otorgar más de la mitad de la expresión al rostro. La conclusión es que, a través de los ojos, Houdon descifraba las almas con la ayuda de los músculos cigomáticos y orbiculares de la boca para que la expresión facial transmitiese estados de ánimo, impresión de firmeza o, en síntesis, la sonrisa satírica que caracteriza a Voltaire.

Las implicaciones de esta identificación permiten asumir que Houdon venía a confirmar los aspectos esenciales del desarrollo autosignificativo en cada uno de sus bustos. Consciente de que la cultura debe ser utilitaria y proyectada en función del bien común, viene a plantear con su obra una consideración que en el caso presente debo admitir que resulta arriesgado comentar estrictamente. Como no es posible resolver todas las cuestiones, la respuesta que interesa surge de dos preguntas, ¿cuáles pudieron haber sido las fuentes para afrontar la sintaxis de la expresión facial?; ¿cuál pudo haber sido el proceso para estructurar la expresividad de los rasgos, de manera que el rostro esté en concordancia con el alma? A este propósito hay una serie de posibilidades relacionadas con teóricos de la época, especializados en la fisiognomía como la ciencia que descubre el carácter a través de los rasgos, considerados en algunos casos precursores de la neuropsiquiatría; por ejemplo Sir Thomas Browne (1605-82), autor de Religio medici, obra leída por Lavater (17411781), cuyos ensayos en alemán fueron traducidos al francés y al inglés. De igual modo, estarían las citadas teorías del jesuita y matemático francés Descartes (Passions de l’Ame) o los planteamientos de Le Brun. Todos estos estudios, entre otros muchos, como los de Johan Caspar (1741-1801), junto con el conocimiento llevado a cabo en Italia por el escultor sobre

PUNSET, Eduardo, El alma está en el cerebro. Radiografía de la máquina de pensar, Biblioteca redes, Barcelona, 2006 (3ª edición); NOBLE, David, F., La religión de la tecnología, Paidós, Transiciones, Barcelona, 1997, pp. 177-180, 182, 192. 
las disecciones faciales, contribuyen a su conocimiento sobre la correlación entre los rasgos físicos y los rasgos de carácter.

$\mathrm{Al}$ establecer una comparación entre el Voltaire de Pigalle (mármol, 1776) con el Voltaire sentado de Houdon (1778, mármol y bronce), en este último lo primero que se observa es una diferencia brillante. Trata de presentar uno de los rasgos más característicos de su creatividad facial, enfocado hacia el desarrollo autoexpresivo de cuanto enlaza con la identidad personal de una mente creativa que, ataviada como un filósofo de la antigüedad, contribuyó a un cambio en la manera de pensar de la Humanidad. Recién llegado a Paris, desde Ferney, en la frontera Suiza, no se corresponde con un desnudo heroico inspirado en el pasado, como tampoco se centra en la decadencia física (tal se percibe en la obra de Pigalle). Voltaire acababa de fallecer a los 84 años y la precisión de su rostro vivo, aunque quedaba ligado a las medidas de su mascarilla, en la apreciación que el espectador hace de la imagen sedente de Houdon, adquiere una experiencia fundamental la relación inequívoca de reposo y de movimiento.

Este proceso impone un desencadenante para interpretar: mirar, siempre sin limitarse a percibir impresiones, sino para llevar a cabo

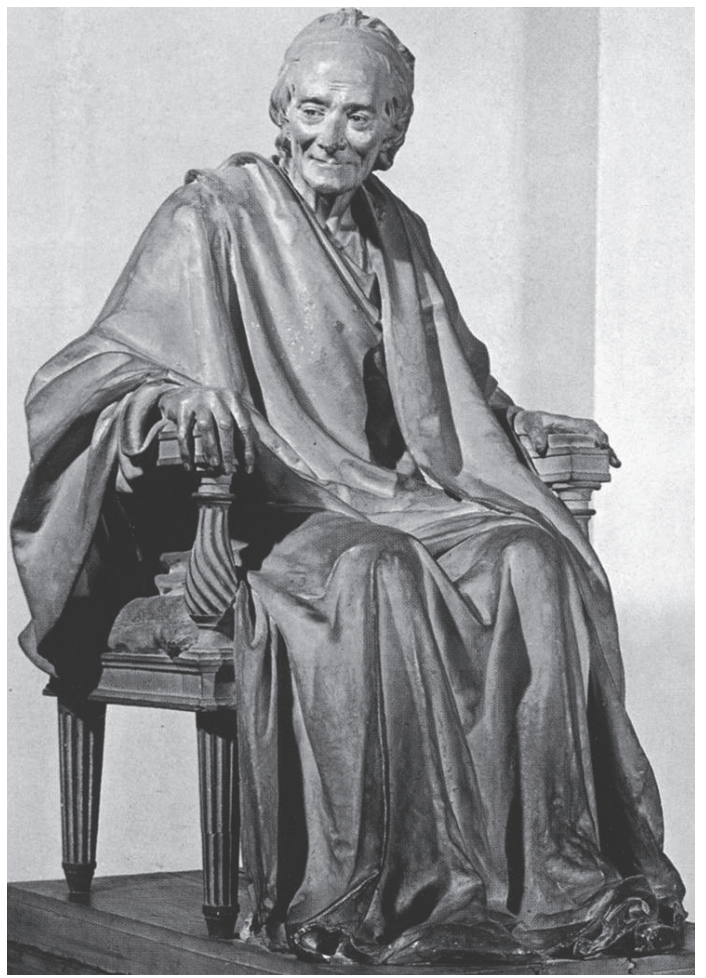

Fig. 4. J. A. Houdon: Voltaire sentado (1781. Paris, Comédie Française) una operación mental para comprender. Circunstancias que obligan a tomar conciencia de la expresión facial y el gesto ilustrador de la sonrisa con el característico cierre ligero de los ojos. Comportamiento kinésico ligado a Voltaire en todos los bustos elaborados por Houdon. Esta sonrisa, ¿expresa felicidad? A. Rodin supo distinguirla como sardónica, mordaz, cáustica, irónica, incisiva...; por eso la impresión que transmite se define como "sonrisa engañosa". Para concluir con este ejemplo tal vez se imponga invocar hasta qué punto Houdon, llegado el momento de elaborar esta obra, no tuvo en cuenta la propia definición de Voltaire sobre la Astucia, en su Diccionario Filosófico:

"la astucia en un sentido figurado se aplica a la conducta, a la conversación, a las obras del espíritu. En la conducta la astucia expresa siempre lo mismo que en las artes, algo sutil... En las obras intelectuales, así como en la conversación, la astucia consiste en el arte de no manifestar expresamente el pensamiento, haciéndolo percibir indirectamente como un enigma que las personas inteligentes adivinan al primer golpe de vista" ${ }^{31}$.

Como puede observarse, tal definición también puede tener su enunciado en las posiciones y en los movimientos corporales que describen el valor comunicativo en esta figura de Voltaire, donde tan importante resulta el lenguaje del cuerpo, incluidas las manos. Como autor de obras de teatro, conviene saber que este filósofo también era conocedor de que un ser humano sin vida deja de ser expresivo ${ }^{32}$.

Antes de abordar otro ejemplo, parece fundamental exponer algunas cuestiones relacionadas con el busto de Voltaire de cabeza desnuda o galea capitis (Museo del Louvre,1778); obra destacada, en primer lugar, por A. Rodin por sus "ojos escudriñadores y por unos hábitos en conexión con la malicia"; si se añade que tuvo en consideración los tres puntos centrales de su envoltura (boca, nariz y rostro), nada hay de sorprendente enque el compendio

31 GONZÁLEZ SEARA, Luis, El poder y la palabra, Tecnos, Madrid, 1995, p. 502, nota 261.

32 Se impone recordar que Voltaire sentado en la Comédie Fraçaise faire pendant con el sillón donde Molière llevó a cabo su última representación, El enfermo imaginario (17 de Febrero 1673). En el mismo hall también se dispuso el busto del propio Molière, elaborado por Houdon en 1781. 
fuera, junto a lo ya expresado anteriormente, la unidad indisoluble del expresivo rostro de "una vieja comadre muy astuta; tal es el efecto producido por este Voltaire a la vez tan astuto, tan enclenque y tan poco masculino". Aun cuando las valoraciones sean ciertas en lo esencial, Houdon parecía tener en consideración las teorías sobre la ciencia que intenta descubrir el carácter a través de los rasgos. Así, en palabras de Sir Thomas Browne, "existe ciertamente una fisionomía..., pues hay ciertos caracteres en nuestros rostros que llevan en ellos el lema de nuestras almas, en los cuales incluso un analfabeto puede leer nuestras naturalezas". Es decir, una impresión sin duda asociada a los planteamientos ya citados de Descartes, como también habría que subrayar la referencia a otras teorías del momento, como la de Lavater o la de Edward Gibbon (Londres, 1752-1794). Para Lavater, a través de la cara puede conocerse el carácter o personalidad; planteamiento no muy distante del utilizado por el pintor Le Brun cuando aplica el estudio fisiognómico en su Método para aprender a dibujar las pasiones (1698). Otro autor de decisiva influencia pudo haber sido el londinense Edward Gibbon. Era un historiador conocido e integrado en los círculos de los ilustrados, como Diderot, D'Alembert, con vínculos amistosos con Voltaire. De posición política conservadora, sus obras escritas guardaban relación con los problemas de identidad sobre el Imperio Romano. En este contexto, al examinar una moneda con la cabeza de Marco Agripa, hizo el siguiente comentario: "creo leer en sus rasgos las cualidades de sinceridad, grandeza y sencillez que caracterizan a un hombre respetable $¿$ Es de verdad tan corriente que el alma de un hombre se refleje

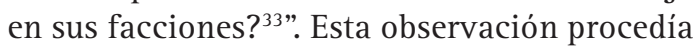
de una persona que conocía al conde Anne Claude de Caylus (1292-1765), miembro y fundador, como es sabido, de la Escuela de Bellas Artes en 1760, coleccionista de antigüedades etruscas, griegas, romanas y galas; pero, sobre todo su atención a la numismática de los emperadores romanos, contribuyó a que su museo fuera un marco de referencia insustituible para el arte neoclásico. Lo que no es fácil saber es, si de lo expuesto podría deducirse que Houdon, en su bajo relieve sobre Apolo empujado por el viento (mármol, 1782)

HASKELL, Francis, op. cit., p. 181. bebe en la obra de Caylus sobre los emperadores romanos, Numismata Aurea Imperatorum Romanorum. En cualquier caso, para concluir este apartado, Gibbon y Caylus eran asimismo seguidores de las teorías del filósofo de Turena sobre las Passions de l'Ame (la sede del alma se ubica en el centro del cerebro).

Los escritos de Lavater, traducidos al francés, "con gran influencia en los artistas y escritores" (A. L. Normand-Romain), eran útiles para analizar expresiones, en concurrencia con los músculos; aunque Houdon, buen conocedor de la correlación entre los rasgos faciales y los rasgos complejos del carácter o personalidad, no haría falta decir que no surgió ex nihilo. Esta propuesta de Voltaire es portadora de indicaciones muy precisas, como la importancia de los músculos orbiculares de párpados y labios, de igual manera que la aponeurosis de la cabeza. Es decir, se trata de resaltar la inherencia alma-cerebro. De manera que el escaño del alma se ubica en la glándula central del cerebro, sobre el entrecejo y el nacimiento de la nariz; un lugar especial para cumplir con las funciones del pensamiento. De manera que los órganos de recepción son ojos, nariz y, en el caso del ciego, las manos. Con la expresión facial, "la ceja, fruncir el ceño", se conceptualiza mejor la emoción, quien determina el estado de ánimo; es decir, la alteración, la exaltación, el temor, el arrebato..., cargas producidas por el desencadenamiento energético en el cerebro y conectadas muchas veces con el padecer, la pasividad, la paciencia, etc. Según parece, estos planteamientos, junto con el reclamo del mundo clásico, suscitaron un manifiesto interés en Houdon, sin dejar de considerar el mundo del teatro (el valor de la mímica, del gesto). Lo expuesto, también se compenetra con la opinión de Seroux d'Agincourt. Era un crítico de arte afecto a Voltaire, Rousseau y Buffon, quien consideraba que las artes se perciben con el sentido de la vista; pero además, añadía, sólo a través de la percepción visual, las múltiples formas de representación artística "dejan su impresión en el alma" ${ }^{34}$.

Entre las cuestiones que plantea el busto dedicado a Molière, llamado Jean-Baptiste Poquelin (1622-1673), existe una de fondo. En 1781 Mr. Haudry encargó un busto en terracota, emparejado con otro. La polémica se des-

$34 \quad$ Ibid., p. 185. 


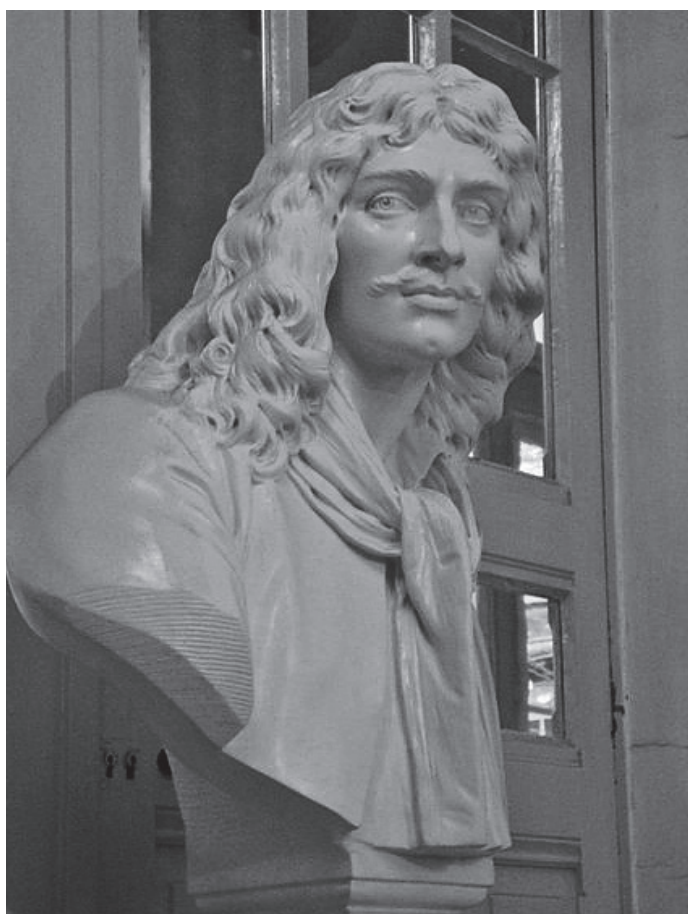

Fig. 6. Molière (1622-1673)

encadenaría muy poco después, al pasarlo de la terracota al mármol, lo que determinaría la ampliación de la parte inferior. En consecuencia, ¿se podría declarar busto de tesis?; el psicologismo en su conjunto se halla escrito en el rostro. Pese a la inmensa notoriedad de la que gozó en su día, en conjunto recuerda un busto del s. XVII.

Estamos ante el que fue actor de gran talento, con cualidades para el drama, la comedia y la farsa; dotado para la literatura, como también con propiedades predominantes para la oratoria, la soltura, la mímica..., la gracia. Guiado por la subjetividad, influenciado por el mundo de la interpretación y su extensa área, la intención de la mirada, parece anular la eficacia de todo mensaje; pasea la vista sin interés en comunicar, como manera de evitar toda atención ante el auditorio. Quien fuera ser expresivo en el escenario con distintas elevaciones de tono en la voz, en la declamación, en el canto y adicto a la risa..., se tiene que marchar a su domicilio, antes de rematar la cuarta representación. El auditorio de la Comédie Française (Paris) no puede ser ajeno ni al lema, como tampoco a la realidad de quien llevó a término una vida inconformista de vivir y de pensar. Si su lema era "corrige tus costumbres riéndote", su semblanza señala a una persona de mente lúcida, crítico con el necio, con el misántropo, el tartufo, el atolondrado... Y, encarnando El enfermo imaginario, llega hasta el preámbulo de su óbito, sin renunciar a su condición de actor; profesión evaluada por la Iglesia como inmoral, al igual que aquellos que fueran juzgados por Molière como monedero falso en su obra Tartufo, en donde denunciaba la abundante hipocresía religiosa.

Pero no menos relevante es que en este expresivo rostro de alguna manera se penetra en la neurología, en el estudio de los músculos del cuello; en concreto la vena yugular, de mucha importancia en la declamación y el canto. No tendría demasiado sentido cuanto se indica, sin detenerse a realizar un breve comentario. El autor sufrió una aguda agresión de hemoptisis durante la representación, para morir en su domicilio. Algunos autores hacen referencia al interés del propio Rodin por lo que definió como la "imagen de la muerte inesperada" (A. L. Normand-Romain). Y para aclarar la pista en tal orientación, se nos indica que, en la Grimace de la Mort, observada en una representación en Marsella, se habría de inspirar para hacer estudios con Hanako. Propuestas que ella misma designó como "cabezas de la muerte, de la meditación, de los celos, de la serenidad. En definitiva, una manera de transmitir los efectos de los distintos estados anímicos".

La cantera de obras elaboradas por Houdon es sumamente amplia. Según Guilhem Scherf los conocimientos alcanzan hasta trescientas conocidas. Entre ellas tiene una dimensión propia la correspondiente a Jean-Jacques Rousseau (1712-1778). Considerado uno de los críticos más agresivos de la vida social del momento e, incluso, como un sexista furibundo, según el análisis de la historiadora Mona Ozouf tal concepto abarca la duda. Así, Olimpia de Gouges, girondina guillotinada en 1793 y autora de la Declaración de los derechos de la mujer y de la ciudadana, al presentar ante la Convención tal declaración (28 de octubre de 1789), denomina a Rousseau públicamente "su padre espiritual". En realidad, en su obra se estaban produciendo cambios; así, en la Nueva Heloisa define lo que la Revolución denominará “despotismo paternal" y hace una defensa vibrante de la tendencia, en la voluntad y hábitos, natural o matrimonio democrático. Considerando que los testimonios sobre su vida llevan emparejada una larga secuencia, parece necesario mirar hacia sus costumbres y creencias. Por tanto, ¿resulta 
difícil saber su concepto sobre el arte y si prestaba atención a los usos posibles de las imágenes? Así como a Voltaire no se le adjudica una valoración explícita, Rousseau en el año 1750 se declaraba a favor de un arte didáctico. ¿En qué sentido? No prestaba atención a los usos posibles de las imágenes con tono mitológico; en realidad, condenaba tal tipo de obras, puesto que su valor reside en el ensalzamiento y encomio, incluso emocional, en el código ético de los ricos inclinados al mundo del boudoir. Por añadidura, crítico con la ciencia tradicional, consideraba que el método científico de Browne a Descartes, no en cambio el de Lavater, no era suficiente para explicar el mundo. En cualquier caso, no tenía el poder o eficacia para resolver sus problemas.

Pero el hombre de imaginación poderosa y creativa tenía también otro criterio: rehuía y se obstinaba a posar, a pesar de las propuestas de su amigo el marqués de Girardin. Solo posteriormente, con la aprobación de la Asamblea Nacional ante su desacato del derecho establecido a la imagen, será el citado marqués quien otorgue a Houdon el privilegio de realizarle la correspondiente mascarilla mortuoria. Referente que, además de garantizar la autenticidad de su busto, pasará a ser el retrato canónico de múltiples ejemplares realizados en su memoria. De nuevo el bustier lograr hacer presente lo ausente al reconstruir una mirada crítica, donde se eluden rasgos de ternura y se impone la triada entereza-severidad-voluntad de una persona cuya obra Emilio había contribuido a educar a los hijos de su amigo. Un libro con indicaciones sobre la personalidad del niño como ente independiente $\mathrm{y}$, a la vez, a quien hay que investir de vida, sin venda en los ojos, lo que implica correlacionar el valor de la instrucción y de la libranza ante la dolencia. Si en las pruebas decisivas de la vitalidad está el énfasis puesto en la mirada, también nos dice con claridad en qué basa su afirmación al evitar la vestimenta clásica o sin vestimenta (Voltaire) y ataviar "al hijo del relojero y de la antigua doméstica, con rostro plebeyo, nariz corta, mentón cuadrado y tosco" (tal era la radiografía hecha por A. Rodin), con casaca a la francesa, camisa de gola, corbata y peluca.

Por último, si buscamos la respuesta a la pregunta sobre el impacto de su óbito, habrá que recurrir a la influencia de sus ideas. Quizá sea el momento de recordar que, antes de su traslado al Panteón y enterrado en su jardín de Ermenonville, entre las personas que acudieron a honrarle, estuvieron María Antonieta, Franklin, Thomas Jefferson, Danton, Chateaubriand, Gustavo III de Suecia... Napoleón ${ }^{35}$.

A medida que cobraba entidad el rechazo al fanatismo religioso, declarando como controvertible el sello divino de los reyes, los privilegios del clero y de la nobleza, se desarrolla una nueva e innovadora iconografía que David Freedberg define en relación a las fiestas de la razón, conforme a la nueva convención de los ilustrados. Esto suponía la sustitución de las fiestas religiosas y, en consecuencia, la de las Vírgenes, ya que en ellas reposaba el símbolo de la realeza. Como consecuencia cobran entidad símbolos de la antigüedad clásica como Diana (Fundación Gulbenkian de Lisboa, 1776; Museo del Louvre, 1790), Morfeo (Museo del Louvre, 1777), Apolo impulsado por el viento (medallón de mármol, Museo del Louvre, 1782)... Esculturas que muchas encuentran su complementariedad en Nicolás Poussin en el prado del jardín del palacio de Versalles.

Sin duda era Diana la diosa virgen especialmente reverenciada el idus de agosto y a la que Houdon caracterizó con una técnica impecable y con una mínima diferencia entre los dos ejemplos conservados: así, la versión en bronce del Museo del Louvre suprime el manojo de cañas para reclamar su atención la anatomía corporal $^{36}$. A menudo se abarcan respuestas que procuran no dañar la versión sobre el tema. En el caso presente, ¿qué carácter tenía esta clase de imágenes? La respuesta que otorga Guilhem Scherf es que la diosa del Louvre fue sometida a efectos de censura, y así leemos: "la administración de Bellas Artes no podía exhibir una cosa tan indecente como la raja bulbar de la casta Diana, por lo que fue tapada, martillada (por no decir atormentada) antes de ser presentada en una exposición en el año 2000 ante el público"37.

Como remate de la presente exposición, y nota aclaratoria al año 1792, momento en que se produce la conclusión de la primera etapa de Houdon, quizás se imponga tener en cuenta

35 Sobre Rousseau se ha editado en 2012 el estudio de Guilhem SCHERF, Severin DARROUSSAT Y Alain CHEVALIER titulado Jean-Jacques Rousseau et son image sculpté, 1778-1798 (Fage Editions, Paris).

36 FREEDBERG, David, op. cit., p. 433.

37 SCHERF, Guilhem, Houdon, sculpteur des Lumières: 1741-1828, Edition de la Réunion des Musées Nationaux, Paris, 2004. 
dos datos. Considerar, en principio, que Houdon y Voltaire estaban asociados a la francmasonería; en ese momento el ensayista católico Le Fran escribió el libro El velo levantado para los inquisitivos, donde se atribuía a esta logia gran parte de los males de la Revolución. En segundo lugar, en 1798 la cuestión se complica todavía más, al ser cuando sale al público el libro del abad Barruel, cuyo título es Memorias para servir a la historia del jacobinismo, obra de pensamiento contrarrevolucionario. Ahora bien, hay algo que no siempre suele indicarse: en criterio de dicho abad, Voltaire, D’Alembert y Federico II de Prusia, guiados por su odio contra el cristianismo, fueron quienes proyectaron el proceso que llevaría hacia la Revolución, y en consecuencia, como quedó indicado en líneas anteriores, el ataque a la Iglesia y al rey. Es decir, se consideraba que Luis XVI no podría sobrevivir con la caída de la Iglesia católica. Esto dio como resultado la denuncia o complot contra los ilustrados, pero, también, contra los francmasones. De todas maneras, en tiempos de Napoleón la francmasonería vuelve a disponer de logias en París ${ }^{38}$.
Por otra parte, para los nostálgicos del Antiguo Régimen, herederos de las teorías de Joseph de Maistre (1753-1821), contemporáneo de la Revolución, con Houdon se había cerrado el círculo de la secta execrable; se entendía como tal a los filósofos de las Luces, a los que adoptaron una manera no conformista de vivir y de pensar, cuestionando la concepción del Cristo del amor; muchas de las cuestiones, puestas en el aire por Moliére en su obra $E l$ Tartufo. No se olvide que este personaje, al que Houdon tuvo en cuenta, durante mucho tiempo fue el ejemplo del libertino por -según sus enemigos- el matrimonio con su hija y obras como La escuela de mujeres.

En estas circunstancias a los pilares opuestos a los seguidores de Maistre, el abad Barruel..., en las proximidades de El Terror (17921794) era fácil denunciarlos, hacer tabla rasa, atacarlos, puesto que lo que se trataba de imponer era lo contrario a la dictadura de la razón y el individualismo. Conceptos que, en definitiva, estuvieron presentes en la obra de Houdon hasta la nueva etapa en tiempos de Napoleón.

38 RIDLEY, Jasper, Los masones, Ediciones B Argentina, Buenos Aires, 2004, pp. 178-226; GENGEMBRE, Gérard, “Les nostalgiques de l'Ancien Régime”, L'Histoire, no 219, mars 1998, pp. 44-45. 